Article

\title{
Low Temperature Resistance Increase for Bitumen by Compounding with Tar
}

\author{
Bagdat Teltayev $^{1, *(\mathbb{D})}$, Tulegen Seilkhanov ${ }^{2}{ }^{\circ}$, Cesare Oliviero Rossi ${ }^{3}{ }^{(0}$, Yerik Amirbayev $^{1}$ \\ and Sakhypzhamal Begaliyeva ${ }^{1}$ \\ 1 Kazakhstan Highway Research Institute, Almaty 050061, Kazakhstan; erik_neo@mail.ru (Y.A.); \\ begalieva_58@mail.ru (S.B.) \\ 2 Department of Chemistry and Biotechnology, Sh. Ualikhanov Kokshetau State University, \\ Kokshetau 020000, Kazakhstan; tseilkhanov@mail.ru \\ 3 Department of Chemistry and Chemical Technologies, University of Calabria, 87036 Rende, Italy; \\ cesare.oliviero@unical.it \\ * Correspondence: bagdatbt@yahoo.com
}

Citation: Teltayev, B.; Seilkhanov, T.; Oliviero Rossi, C.; Amirbayev, Y.; Begaliyeva, S. Low Temperature Resistance Increase for Bitumen by Compounding with Tar. Appl. Sci. 2021, 11, 8579. https://doi.org/ 10.3390/app11188579

Academic Editors: Luís Picado Santos and Doo-Yeol Yoo

Received: 3 August 2021

Accepted: 13 September 2021

Published: 15 September 2021

Publisher's Note: MDPI stays neutral with regard to jurisdictional claims in published maps and institutional affiliations.

Copyright: (c) 2021 by the authors. Licensee MDPI, Basel, Switzerland. This article is an open access article distributed under the terms and conditions of the Creative Commons Attribution (CC BY) license (https:/ / creativecommons.org/licenses/by/ $4.0 /)$.

\begin{abstract}
In this paper, a conventional road bitumen with penetration grade 100-130 is compounded with tar in order to obtain bitumen with improved low temperature resistance. The low temperature (at $-24{ }^{\circ} \mathrm{C},-30{ }^{\circ} \mathrm{C}$ and $-36{ }^{\circ} \mathrm{C}$ ) resistance of the virgin bitumen and the compounded one is evaluated by testing on a bending beam rheometer. It was found that the optimum compounding ( $20 \%$ of tar by weight) decreases the stiffness essentially (from $18 \%$ to $34 \%$ ), i.e., it increases the low temperature resistance of the bitumen. The stiffness decreases in the compounded bitumen can be explained by quantitative variations in its group chemical composition and molecular fragments. Group chemical composition has been determined by the method of absorption chromatography, and the fragments of molecules are identified by NMR-spectroscopy.
\end{abstract}

Keywords: bitumen; tar; compounding; bending beam rheometer; stiffness; group chemical composition; NMR-spectroscopy

\section{Introduction}

Bitumen is one of the materials widely used in road construction all over the world. It is known that the operational characteristics of road asphalt concretes are mostly determined by the properties of bitumen [1-5].More strict requirements are specified relative to the properties of the bitumen used in sharp continental climatic conditions [6,7]. In such climatic conditions, the asphalt concrete with bitumen should have sufficient resistance to the rutting under numerous repeated impact of heavy trucks in a hot summer season and to low temperature cracking at sharp, continuous and cyclic cooling in a cold winter season.

In order to improve the operational properties (resistance to rutting and low temperature cracking) of asphalt concretes, bitumens are modified with different polymers [8-15]. However, polymers, as a rule, essentially increase only high temperature resistance (resistance to the formation of plastic deformations) of asphalt concretes. Currently, the plants of Kazakhstan produce bitumens only with penetration grades 70-100 and 100-130. Low temperature cracks occur on pavements constructed with the use of bitumens of these grades (especially in the northern and eastern regions) during the first winter, and the number of them has increased from year to year. Meanwhile, it is known that bitumens of less viscous consistence have comparatively better low temperature characteristics.

The objective of the paper is low temperature resistance increase for bitumen by compounding with tar.

A review of the literature shows that the number of works devoted directly to the compounding of road bitumen with tar is extremely limited. Apparently, it can be explained by the fact that researchers of bitumen binders, as a rule, work with bitumen produced by 
the plants. One of the causes for the limited amount of the investigations for this subject is perhaps connected with the increase in environmental requirements relative to the asphalt concrete pavements due to the content in them of the cancerogenic polynuclear aromatic hydrocarbons, which can be the source for contamination of soils and underground water [16-18]. However, the materials discussed below show the potential for road bitumen production using the tar. For example, in 2007, a patent [19] was issued in Russia for a method of producing the compounded bitumen, which provides mixing at a temperature of 110-130 ${ }^{\circ} \mathrm{C}$ for $10-15 \mathrm{~min}$ of tar and more viscous oil refining residue at the ratio of 20:80 by weight. Moreover, a method is patented for obtaining road bitumen of the grade 60-90 on penetration, which is realized by the compounding of oxidized bitumen with penetration $\mathrm{P}_{25}=550.1 \mathrm{~mm}$ and softening point $\mathrm{T}_{\mathrm{RB}}=66^{\circ} \mathrm{C}$ with tar (conditional viscosity $42 \mathrm{~s}$ ) at the temperature of $160-180{ }^{\circ} \mathrm{C}$ at the ratio of $80: 20$ by weight [20]. Another method [21] is known, according to which a two-stage process is used to obtain road bitumen with the softening point $\mathrm{T}_{\mathrm{RB}}=75^{\circ} \mathrm{C}$ : at the first stage, a mixture of tar and asphaltite at the ratio of $50: 50$ by weight is compounded for $40 \mathrm{~min}$ at the temperature of $140{ }^{\circ} \mathrm{C}$; at the second stage the obtained compounded mixture of the tar and the asphaltite is subjected to oxidation in a column at the temperature of $250-270{ }^{\circ} \mathrm{C}$ for $7 \mathrm{~h}$.

The possibility for the obtaining of polymer modified (SBS) road bitumen with improved characteristics, also using oxidized bitumen with penetration grade 70-100 and high-viscosity tars $\left(\mathrm{P}_{25}=95\right.$ and $\left.1100.1 \mathrm{~mm}\right)$, is given in a recently published paper [22].

Considering the above, in this work a viscous road bitumen with penetration grade $100 / 130$, conventionally used in a road construction, is compounded with tar to obtain bitumen with improved low temperature operational characteristics. The low temperature (at $-24{ }^{\circ} \mathrm{C},-30{ }^{\circ} \mathrm{C}$ and $-36{ }^{\circ} \mathrm{C}$ ) resistances of the virgin bitumen and the compounded one are evaluated by testing on a bending beam rheometer. The essential increase has been determined for the low temperature resistance of the compounded bitumen of optimum composition compared with the virgin bitumen, and it can be explained by quantitative variations in the group chemical composition and molecular fragments of the bitumen at compounding. Group chemical composition of the bitumens has been determined by absorption chromatography, and the fragments of molecules are identified by NMR-spectroscopy.

\section{Materials and Methods}

\subsection{Bitumen}

A road viscous bitumen with penetration grade 100-130 has been selected for compounding with tar. The bitumen has been produced by the Pavlodar petrochemical plant (Kazakhstan) from the oil of Western Siberia (Russia) by direct oxidation. The bitumen satisfies the requirements of ST RK 1373-2013 [23]. The main standard indicators are represented in Table 1. More detailed information regarding the characteristics of the bitumen is included into the works $[6,24]$.

Table 1. Main standard indicators of the virgin bitumen.

\begin{tabular}{cccc}
\hline Indicator & Measurement Unit & Standard & Value \\
\hline Penetration $\left(25^{\circ} \mathrm{C}\right)$ & $0.1 \mathrm{~mm}$ & ST RK 1226-2003 & 116 \\
Ductility $\left(25^{\circ} \mathrm{C}\right)$ & $\mathrm{cm}$ & ST RK 1374-2005 & 115 \\
Softening point & ${ }^{\circ} \mathrm{C}$ & ST RK 1227-2003 & 45 \\
Fraas point & ${ }^{\circ} \mathrm{C}$ & ST RK 1229-2003 & -27 \\
Penetration index & - & ST RK 1226-2003 & -0.312 \\
Dynamic viscosity & $\mathrm{Pa} \cdot \mathrm{S}$ & ST RK 1211-2003 & 138 \\
\hline
\end{tabular}

\subsection{Tar}

The tar used for compounding the bitumen with penetration grade 100-130 was delivered from the Pavlodar petrochemical plant as well. The tar satisfies the requirements of ST RK 3337-2018 [25]. The main standard indicators of the tar are represented in Table 2. 
In this paper, the amount of tar added to the bitumen was 5\%, $10 \%, 15 \%, 20 \%, 25 \%, 27 \%$ and $30 \%$ by weight of the virgin bitumen.

Table 2. Main standard indicators of the tar.

\begin{tabular}{cccc}
\hline Indicator & Measurement Unit & Standard & Value \\
\hline Conditional viscosity $\left(80^{\circ} \mathrm{C}\right)$ & $\mathrm{s}$ & ST RK 1683-2007 & 82 \\
Density $\left(20 \pm 2{ }^{\circ} \mathrm{C}\right)$ & $\mathrm{kg} / \mathrm{m}^{3}$ & ST RK 2114-2011 & 956 \\
Flash point & ${ }^{\circ} \mathrm{C}$ & ST RK 1804-2008 & 280 \\
Water content & $\%$ & ST RK 1375-2005 & 0 \\
\hline
\end{tabular}

\subsection{Compounding}

The compounding of virgin bitumen with penetration grade 100-130 and the tar has been performed in the laboratory of the Kazakhstan Highway Research Institute by means of an electric mixer (rotation rate is equal to $450-500$ revolutions per minute) with an electric hot plate.

The technology for preparation of the compounded bitumen has been performed as follows:

1. A sample of the virgin bitumen with penetration grade 100-130 has been selected in the required volume and prepared for compounding;

2. The virgin bitumen was gradually heated up to the temperature of $120^{\circ} \mathrm{C}$;

3. A previously prepared portion of the tar has been added at the mixing of the sample of the virgin bitumen with the rate of 450-500 revolutions per minute;

4. The virgin bitumen and the tar were mixed at a steady pace with the rate of 450-500 rotations per minute at the constant temperature of $120^{\circ} \mathrm{C}$ for $30-40 \mathrm{~min}$;

5. The prepared portion of the compounded bitumen cooled down to room temperature.

The compounded bitumens have been prepared with the content of the tar at 5, 10, 15, $20,25,27$ and $30 \%$ of bitumen weight.

\subsection{Bitumen Aging}

In accordance with the requirements of the Superpave technical system, road bitumens, before testing on a bending beam rheometer (BBR), are subjected to double (short-term and long-term) aging [26-28].

Short-term aging of the neat bitumen and the compounded one has been performed under the standard AASHTO T 240-13 [29]: the bitumen samples have been cured in the vertical rolling thin film oven (RTFOT) at a temperature of $163^{\circ} \mathrm{C}$ for $85 \mathrm{~min}$.

Long-term aging of the neat bitumen and the compounded one has been performed under the standard ASTM D 6521-08 [30]: the bitumen samples that passed short-term aging have been cured in the special pressure aging vessel (PAV) under the pressure of $2070 \mathrm{kPa}$ at the temperature of $100^{\circ} \mathrm{C}$ for $20 \mathrm{~h}$.

\subsection{Bending Beam Rheometer}

After double aging (RTFOT + PAV), the virgin bitumen and the compounded one have been tested on the bending beam rheometer (Figure 1) at three low temperatures $\left(-24^{\circ} \mathrm{C}\right.$, $-30^{\circ} \mathrm{C}$ and $-36^{\circ} \mathrm{C}$ ) under the standard ASTM D 6648-08 [31].

By using the measured values of the maximum deflection of the beams, the bitumen stiffness has been calculated with the following formula:

$$
S(t)=\frac{P \cdot \ell^{3}}{4 \cdot b \cdot h^{3} \cdot \delta(t)}
$$

where $S(t)$ is the bitumen stiffness at time moment $t, \mathrm{MPa} ; \delta(t)$ is a maximum deflection of the bitumen beam at a time moment $(t), \mathrm{mm} ; P$ is a load equal to $0.98 \mathrm{~N} ; h, b$ and $\ell$ are the height, width and length of a bitumen beam, respectively, $\mathrm{mm}$. 


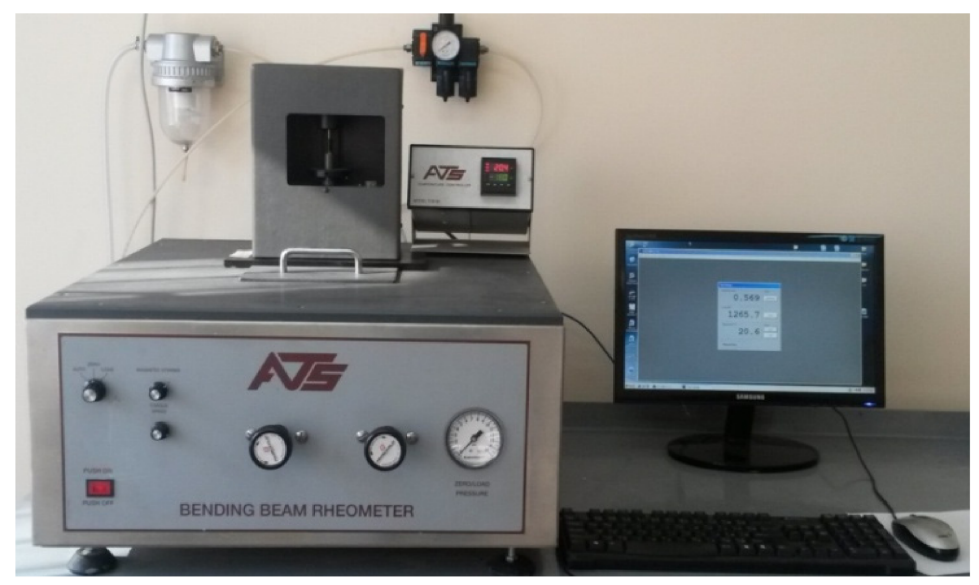

Figure 1. Bending beam rheometer (BBR).

\subsection{Group Chemical Composition of Bitumen}

Group chemical composition was determined by adsorption chromatography method [1,32]. According to this method, asphaltenes are determined by double deposition of a bituminous mortar $(5 \mathrm{~g})$ and $\mathrm{n}$-heptane $(200 \mathrm{~g})$. The remainder of hydrocarbon mixture, consisting of resins and oils, is placed sequentially in a glass chromatograph column filled with large-pore silica gel. For desorption, the dissolvents consisting of n-heptane and benzene are supplied in mass ratios: 90/10; 85/15; 80/20; 75/25; and 70/30. A refraction coefficient is determined for each fraction obtained by adsorption separation. It is accepted that lighter fractions for which the refraction coefficient can be determined belong to oils. The highly colored fractions possessing solid consistency for which the refraction coefficient cannot be determined are resins.

\subsection{NMR-Spectroscopy}

In this work, nuclear magnetic resonance (NMR) spectra of hydrogen ${ }^{1} \mathrm{H}$ and carbon ${ }^{13} \mathrm{C}$ nuclei contained in the virgin bitumen, tar and the compounded bitumen were determined on a JNM-ECA Jeol 400 spectrometer (Japan) at the temperature of $25^{\circ} \mathrm{C}$. The operating frequencies for nuclei ${ }^{1} \mathrm{H}$ and ${ }^{13} \mathrm{C}$ were assumed to be $399.78 \mathrm{MHz}$ and $100.53 \mathrm{MHz}$, respectively. Samples of the virgin bitumen, tar and the compounded bitumen weighing $60 \mathrm{mg}$ were dissolved in $0.5 \mathrm{~mL}$ deuterated chloroform $\left(\mathrm{CDCl}_{3}\right)$.

The chemical shifts of the nuclei ${ }^{1} \mathrm{H}$ and ${ }^{13} \mathrm{C}$ were measured in relation to the signals of residual protons or carbon atoms of deuterated chloroform.

The limits of chemical shifts of nuclei ${ }^{1} \mathrm{H}$ and ${ }^{13} \mathrm{C}$ used for identification and determination of functional groups in the bitumens and tar $[33,34]$ are given in Tables 3 and 4 .

Table 3. Variation limits and interpretation of chemical shifts of ${ }^{1} \mathrm{H}$ nuclei.

\begin{tabular}{|c|c|c|}
\hline $\begin{array}{c}\delta\left({ }^{1} \mathrm{H}\right), \\
\text { ppm }\end{array}$ & Notation of Atoms & Functional Group \\
\hline $0.5-1.0$ & $\mathrm{H}_{\gamma}$ & $\begin{array}{l}\text { Methyl groups of saturated compounds. Methyl groups } \\
\text { in } \gamma \text { and further positions to an aromatic ring. }\end{array}$ \\
\hline $1.0-2.0$ & $\mathrm{H}_{\beta}$ & $\begin{array}{l}\text { Methylene and methine groups of saturated compounds. } \\
\text { Atoms of hydrogen in methyl groups in } \beta \text { position to an } \\
\text { aromatic ring. } \\
\text { Atoms of hydrogen of methylene and methine groups in } \\
\beta \text { and further positions to the aromatic ring. }\end{array}$ \\
\hline $2.0-4.0$ & $\mathrm{H}_{\alpha}$ & $\begin{array}{l}\text { Atoms of hydrogen in } \alpha \text { position to aromatic and } \\
\text { carbonyl carbons, heteroatoms }\end{array}$ \\
\hline $4.5-6.3$ & $\mathrm{H}_{\mathrm{a} \ell}$ & Atoms of hydrogen of olefin groups \\
\hline $6.3-9.0$ & $\mathrm{H}_{\mathrm{ar}}$ & $\begin{array}{l}\text { Atoms of hydrogen of aromatic nuclei and } \\
\text { phenol hydroxils }\end{array}$ \\
\hline
\end{tabular}


Table 4. Variation limits and interpretation of chemical shifts of ${ }^{13} \mathrm{C}$ nuclei.

\begin{tabular}{ccl}
\hline $\begin{array}{c}\delta\left({ }^{13} \mathbf{C}\right), \\
\mathbf{p p m}\end{array}$ & Notation of Atoms & \multicolumn{1}{c}{ Functional Group } \\
\hline $7-17$ & $\mathrm{C}_{\mathrm{pm}}$ & $\begin{array}{l}\text { Atoms of carbon of methyl groups connected } \\
\text { with a methylene group. }\end{array}$ \\
$17-25$ & $\mathrm{C}_{\mathrm{pa}}$ & $\begin{array}{l}\text { Atoms of carbon of methyl groups connected } \\
\text { with a methine group or an aromatic ring. }\end{array}$ \\
$25-50$ & $\mathrm{C}_{\mathrm{a} \ell}$ & Quaternary aliphatic atoms of carbon. \\
\hline
\end{tabular}

The relative number of hydrogen and carbon atoms belonging to the respective functional groups can be calculated by integrating spectra within the specified chemical shifts (Tables 3 and 4).

The total integral intensities of the signals of hydrogen and carbon atoms are calculated with the following expressions, respectively.

$$
\begin{gathered}
\bar{H}_{\text {sum }}=H_{a r}+H_{\alpha}+H_{\beta}+H_{\gamma}, \\
\bar{C}_{\text {sum }}=C_{p m}+C_{p \alpha}+C_{a \ell} .
\end{gathered}
$$

The contents (\%) of aromatic and aliphatic hydrogen atoms are determined by the following formulas, respectively.

$$
\begin{gathered}
\bar{H}_{\alpha r}=\frac{H_{\alpha r}}{\bar{H}_{\text {sum }}} \cdot 100 \%, \\
\bar{H}_{a \ell}=\frac{H_{\alpha}+H_{\beta}+H_{\gamma}}{\bar{H}_{\text {sum }}} \cdot 100 \% .
\end{gathered}
$$

The contents (\%) of hydrogen atoms $\mathrm{H}_{\alpha}, \mathrm{H}_{\beta}$ and $\mathrm{H}_{\gamma}$ are determined with the following formulas, respectively.

$$
\begin{aligned}
\bar{H}_{\alpha} & =\frac{H_{a}}{\bar{H}_{\text {sum }}} \cdot 100 \%, \\
\bar{H}_{\beta} & =\frac{H_{\beta}}{\bar{H}_{\text {sum }}} \cdot 100 \%, \\
\bar{H}_{\gamma} & =\frac{H_{\gamma}}{\bar{H}_{\text {sum }}} \cdot 100 \% .
\end{aligned}
$$

The contents (\%) of carbon atoms $C_{p m}, C_{p a}$ and $C_{a l}$ are determined with the following formulas, respectively.

$$
\begin{aligned}
& \bar{C}_{p m}=\frac{C_{p m}}{\bar{C}_{\text {sum }}} \cdot 100 \%, \\
& \bar{C}_{p \alpha}=\frac{C_{p \alpha}}{\bar{C}_{\text {sum }}} \cdot 100 \%, \\
& \bar{C}_{\alpha \ell}=\frac{C_{\alpha \ell}}{\bar{C}_{\text {sum }}} \cdot 100 \% .
\end{aligned}
$$

\section{Results and Discussion}

\subsection{Bitumen Stiffness}

In accordance with the requirements of the standard of Kazakhstan ST RK 1373-2013, as well as in many countries of the world, the grade of a road bitumen is determined under the penetration value of $25^{\circ} \mathrm{C}$, which evaluates indirectly the consistency (viscosity) of bitumen. Table 5 represents the penetration values of the compounded bitumen at different tar contents. As it is observed, bitumen penetration continuously decreased with tar content increase. It was to be expected, as bitumen viscosity decreased with tar content 
increase. Thus, it was impossible to determine the optimal tar content in the compounded bitumen according to penetration variation, as it required the use of another, more modern test method.

Table 5. Bitumen penetration at different tar contents.

\begin{tabular}{|c|c|c|c|c|c|c|c|c|}
\hline $\begin{array}{c}\text { Tar } \\
\text { Content, \% }\end{array}$ & 0 & 5 & 10 & 15 & 20 & 25 & 27 & 30 \\
\hline $\begin{array}{c}\text { Penetration at } 25^{\circ} \mathrm{C}, \\
0.1 \mathrm{~mm}\end{array}$ & 116 & 118 & 128 & 160 & 170 & 182 & 203 & 216 \\
\hline
\end{tabular}

Currently, in road science and practice, one of the generally accepted and reliable methods for the evaluation of deformability of both virgin and modified bitumen at low temperatures is testing them on a bending beam rheometer (BBR). Meanwhile, bitumen with less stiffness is considered more crack-resistant at low temperatures.

The stiffness values of the tested virgin and compounded bitumens with a load duration of $60 \mathrm{~s}$ at the temperatures of $-24{ }^{\circ} \mathrm{C},-30{ }^{\circ} \mathrm{C}$ and $-36{ }^{\circ} \mathrm{C}$ are shown in Figure 2 . As it can be observed, the compounding effect is stronger with the decrease in temperature and at the tar content of $20 \%$ and more; the stiffness of the compounded bitumen remains constant at all the low temperatures considered. Therefore, tar content equal to $20 \%$ by weight is considered as the optimal one when compounding the selected road viscous bitumen with penetration grade 100-130.

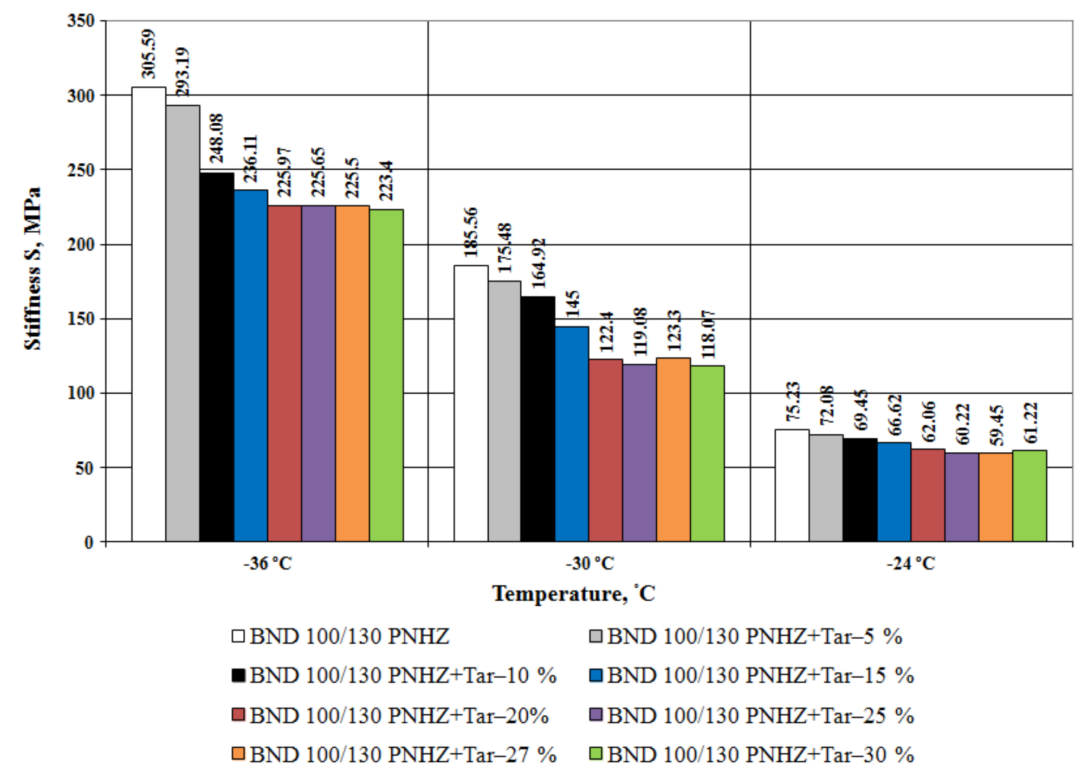

Figure 2. Bitumen stiffness at various tar contents and different temperatures.

The graphs showing the m-value (relaxation rate) of the bitumens at different tar contents and the considered low temperatures are represented in Figure 3. In spite of some scatter, it is clearly observed that $\mathrm{m}$-value decreased with tar content increase at all the considered temperatures. However, even at tar content $30 \%$ at all the considered temperatures, the $\mathrm{m}$-value is more than 0.3 , which is the minimum allowable value according to Superpave. It follows that the selection of optimum tar content in the bitumen according to the stiffness is the justified one.

Figures 4-6 represent the graphs showing a variation in stiffness of the virgin bitumen and the compounded one ( $20 \%$ of the tar) in time at the temperatures considered. It can be observed that during the entire time period considered (240 s) at all test temperatures, the stiffness of the compounded bitumen of the optimal composition is obviously lower (from $18 \%$ to $34 \%$ ) than that one of the neat bitumen. 


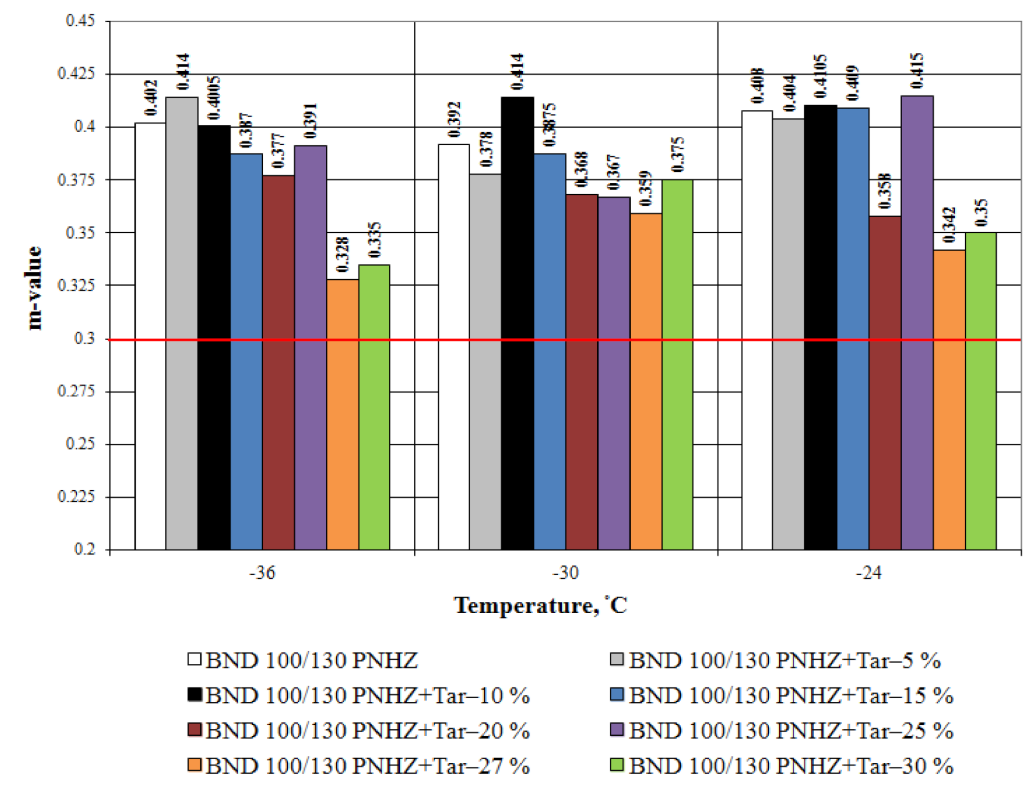

Figure 3. Them-value of the bitumen at various tar contents and different temperatures.

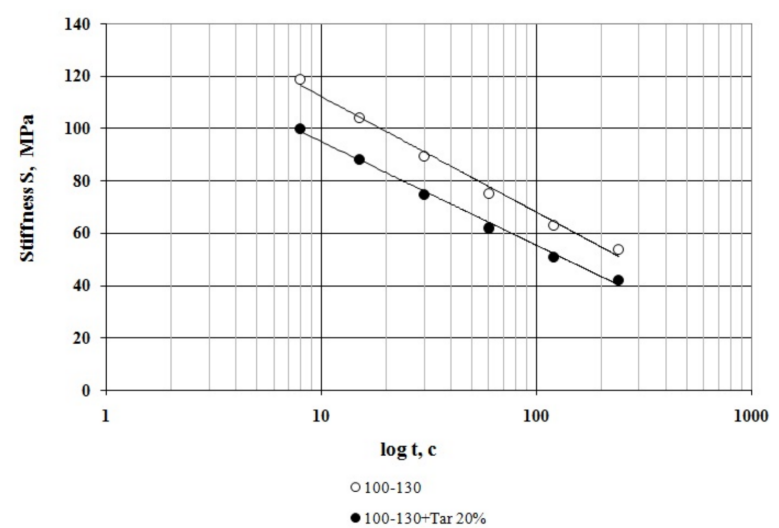

Figure 4. Stiffness variation of the virgin bitumen and the compounded one ( $20 \%$ of the tar) in time at the temperature of $-24{ }^{\circ} \mathrm{C}$.

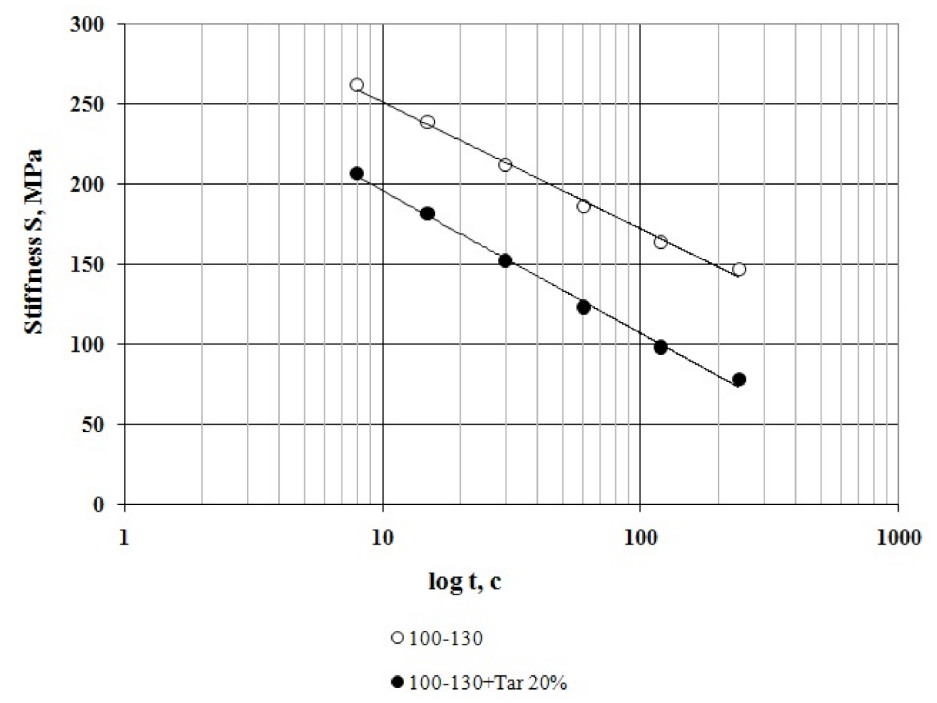

Figure 5. Stiffness variation of the virgin bitumen and the compounded one ( $20 \%$ of the tar) in time at the temperature of $-30{ }^{\circ} \mathrm{C}$. 


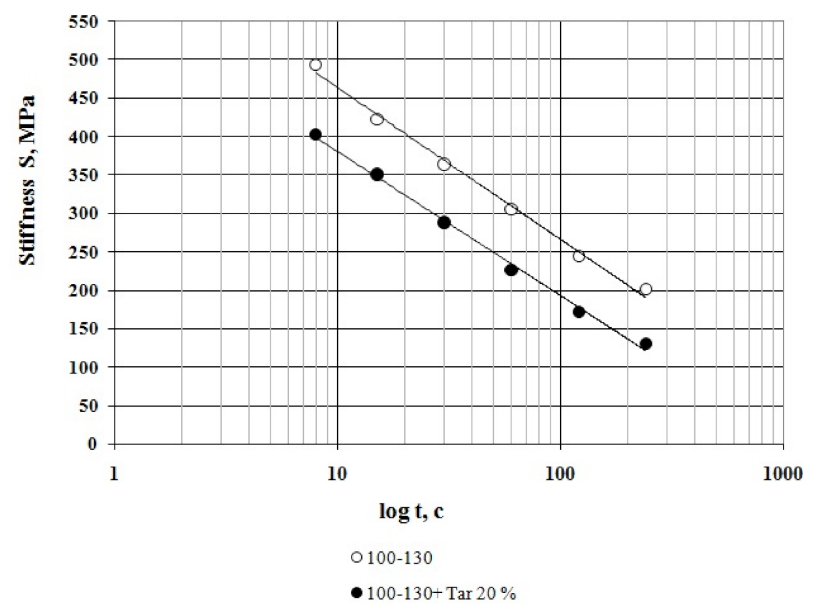

Figure 6. Stiffness variation of the virgin bitumen and the compounded one ( $20 \%$ of the tar) in time at the temperature of $-36{ }^{\circ} \mathrm{C}$.

The results of the BBR bitumen test render it possible to conclude that the compounded bitumen of the optimal composition has increased low-temperature stability.

\subsection{Standard Indicators of Bitumens}

The main standard indicators for the compounded bitumen of optimal composition are given in Table 6. Comparing them with similar indicators of the virgin bitumen, it has been found that the penetration of the compounded bitumen has been increased by 54 decimillimeters, as a result of which, in accordance with the requirements of ST RK 1373-2013 [23], the bitumen changed the original grade of 100-130 to the grade of 130-200; softening point and dynamic viscosity decreased by $5{ }^{\circ} \mathrm{C}$ and $65 \%$, respectively; the Fraas point decreased for $1^{\circ} \mathrm{C}$; and the ductility increased by $10.4 \%$.

Table 6. Main standard indicators of the virgin and compounded ( $20 \%$ of the tar) bitumens.

\begin{tabular}{ccccc}
\hline Indicator & $\begin{array}{c}\text { Measurement } \\
\text { Unit }\end{array}$ & Standard & $\begin{array}{c}\text { Value } \\
\text { Virgin } \\
\text { Bitumen }\end{array}$ & $\begin{array}{c}\text { Compounded } \\
\text { Bitumen }\end{array}$ \\
\hline Penetration $\left(25^{\circ} \mathrm{C}\right)$ & $0.1 \mathrm{~mm}$ & ST RK 1226-2003 & 116 & 170 \\
Ductility $\left(25^{\circ} \mathrm{C}\right)$ & $\mathrm{cm}$ & ST RK 1374-2005 & 115 & 127 \\
Softening point & ${ }^{\circ} \mathrm{C}$ & ST RK 1227-2003 & 45 & 40 \\
Fraas point & ${ }^{\circ} \mathrm{C}$ & ST RK 1229-2003 & -27 & -28 \\
Penetration index & - & ST RK 1226-2003 & -0.312 & -0.962 \\
Dynamic viscosity & Pa·s & ST RK 1211-2003 & 138 & 49 \\
\hline
\end{tabular}

Thus, optimal compounding (20\% of the tar) significantly changes the main standard characteristics of the bitumen, and the obtained compounded bitumen of optimal composition transforms into a more "liquid" penetration grade 130-200.

In Section 3.1, the results for the analysis of the stiffness and m-value of the compounded bitumen at low temperatures allowed determining the optimum tar content. Certainly, it would be desirable to consider the bitumen characteristics at high temperatures as well to justify the optimum tar content.

In Kazakhstan, the high temperature resistance of the road bitumens is characterized by a softening point [23]. Table 7 shows the values for the softening point of the compounded bitumen at different tar contents. As could be expected, the softening point of the bitumen decreased with tar content increase. According to the standard ST RK 1373-2013 [23] for bitumen with penetration grade 130-200, the softening point should not be lower than $40^{\circ} \mathrm{C}$. As observed from Table 7, the maximum allowable (i.e., optimum) tar content in the compounded bitumen is equal to $20 \%$, which with a high accuracy coincides with the optimum tar content determined at low temperatures. 
Table 7. Bitumen softening point at different tar contents.

\begin{tabular}{ccccccccc}
\hline Tar Content, $\%$ & 0 & 5 & 10 & 15 & 20 & 25 & 27 & 30 \\
\hline $\begin{array}{c}\text { Measurement } \\
\text { Temperature, }\end{array}{ }^{\circ} \mathrm{C}$ & 45.0 & 44.5 & 43.0 & 40.5 & 40.0 & 38.0 & 37.8 & 36.6 \\
\hline
\end{tabular}

\subsection{Chemical Structure of Bitumens}

This subsection explains the increased low temperature stability of the compounded bitumen compared to the original virgin bitumen based on a comparative analysis of their chemical structure.

\subsubsection{Group Chemical Composition}

Currently, an explanation of the physical, mechanical and rheological characteristics of bitumens based on their group chemical composition is generally accepted among road specialists [1-3]. According to the concept of a group chemical composition, the entire complex chemical structure of bitumens is divided into two groups: asphaltenes and maltenes; maltenes, in turn, are divided into resins and oils.

Asphaltenes make up the highest molecular weight part of bitumens: black solids are not dissolved in light alkanes (n-pentane, n-hexane, n-heptane, petroleum ether, etc.), they are dissolved in carbon disulfide and chloroform. Asphaltenes are aggregates of flat condensed naphthenic and aromatic molecules (usually 4-6 layers), which are parallel above one another with the inclusion of heterocycles mainly with sulfur and nitrogen, they also contain lateral substituents in the form of limit aliphatic chains and naphthenic rings [1,35-38].

Oils are the lightest fractions of bitumen. The oils are a viscous yellow liquid on their external view. They contain paraffinic and naphthenic compounds and aromatic (monocyclic, bicyclic and polycyclic) hydrocarbons.

Resins occupy an intermediate position between asphaltenes and oils according to their degree of condensation. They are solid or paste-like substances of reddish-brown color. Compared to oils, resins contain more condensed hydrocarbons and heteroatoms. The viscosity of the resins is substantially greater than that of the oils.

From the above brief characteristics of asphaltenes, resins and oils, one can understand that their content ratios determine the degree ofplasticity of bitumen at low temperatures and, therefore, their low temperature stability.

External views of asphaltenes, resins and oils of the compounded bitumen of optimal composition are shown in Figure 7. Figure 8 shows the group chemical compositions of unaged samples of the virgin bitumen, tar and the compounded bitumen. As can be observed, virgin blown bitumen contains $17.4 \%$ of asphaltenes, $26 \%$ of resins and $56.6 \%$ of oils; tar is characterized by significantly lower content of asphaltenes $(4.1 \%)$ and relatively large contents of resins (33.9\%) and oils (62\%). When tar is added to neat bitumen in the amount of $20 \%$ by weight, the compounded bitumen is obtained, which has the following group chemical composition: asphaltenes-13.4\%; resins-23.7\%; oils-62.9\%.

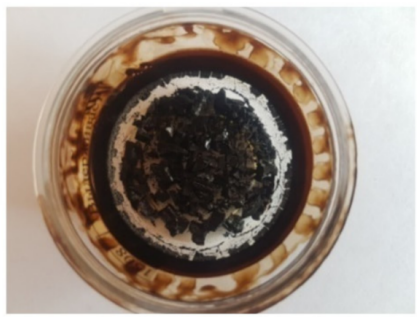

Asphaltenes

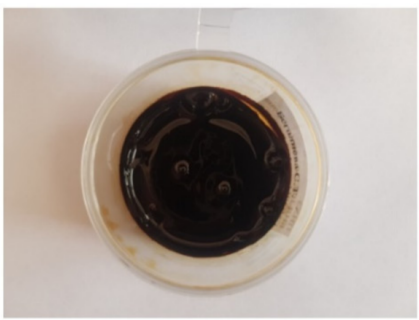

Resins

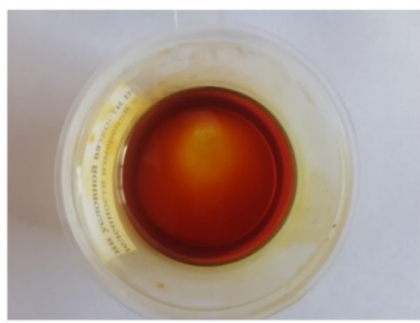

Oils

Figure 7. External view of asphaltenes, resins and oils of the compounded bitumen. 


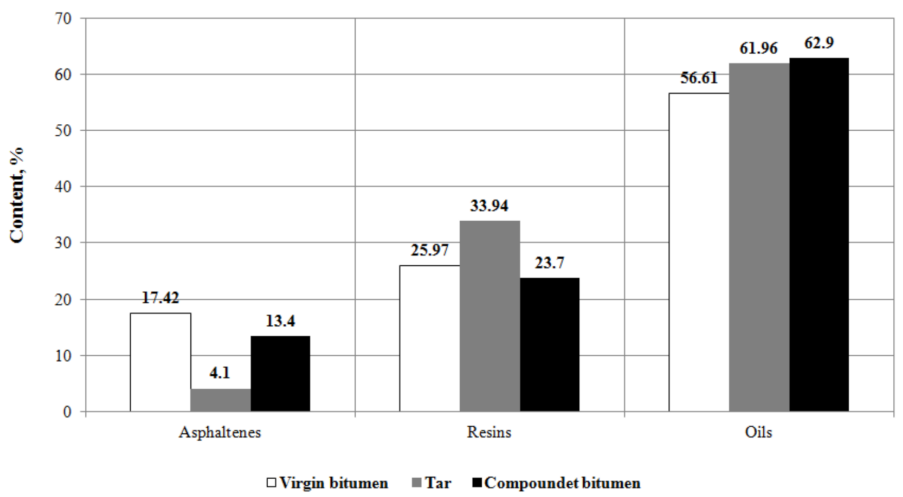

Figure 8. Group chemical compositions of the bitumens.

The above variations in the group chemical composition of the bitumen after compounding compared with the virgin bitumen point to the chemical reactions proceeding between molecular of the bitumen and the tar during compounding.

It should be noted that the contents of resins in the virgin bitumen and the tar were equal to $26 \%$ and $33.9 \%$, respectively. After compounding with tar, the content of resins was $23.7 \%$. As the process of compounding was performed at a high temperature $\left(120^{\circ} \mathrm{C}\right)$, at intensive mixing (450-500 revolutions per minute) and at a duration of 30-40 $\mathrm{min}$ for the compounding, one can suppose that there is an interaction between the molecules of the bitumen and the tar, and the component composition variation occurs as the result of it and part of resins transfers into oils.

Thus, optimal compounding of the bitumen with the tar ( $20 \%$ by weight) changes significantly its group chemical composition: asphaltenes and resins decreased by $23 \%$ and $8.8 \%$, respectively, and oils increased by $11.1 \%$, i.e., the content of solid and highviscosity components of the bitumen significantly decreased, and the content of its lowviscosity components, on the contrary, increased. It was this change in the group chemical composition that resulted in a significant increase in the low temperature stability of the bitumen.

\subsubsection{Fragments of Molecules}

The spectra of atoms of hydrogen ${ }^{1} \mathrm{H}$ and carbon ${ }^{13} \mathrm{C}$ constructed according to the results of measurement of the corresponding chemical shifts for the virgin bitumen (a), $\operatorname{tar}(\mathrm{b})$ and the compounded bitumen (c) are shown in Figures 9 and 10.

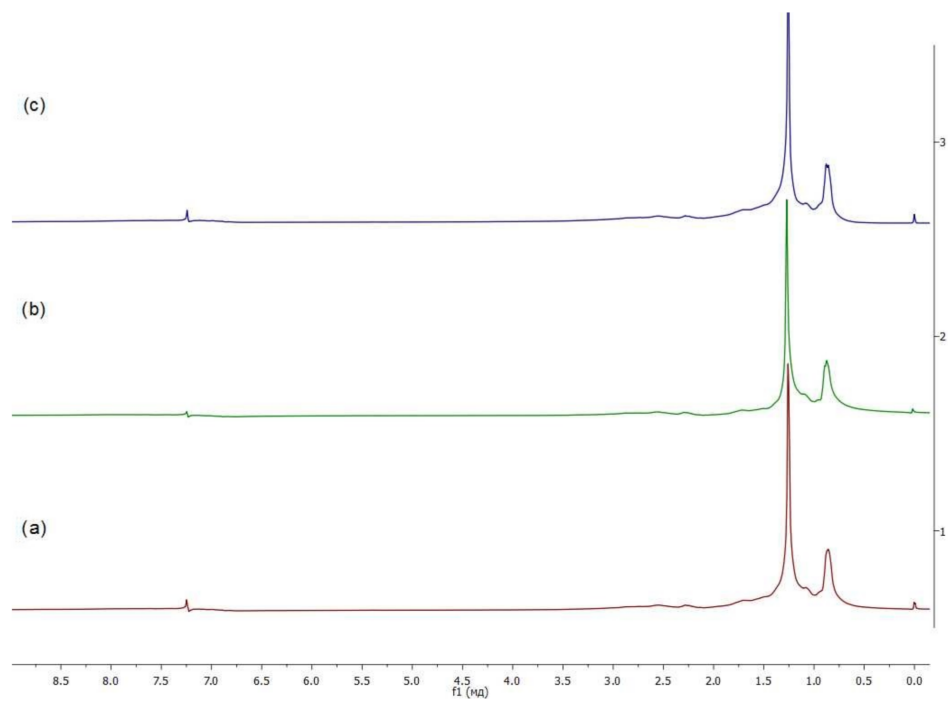

Figure 9. ${ }^{1} \mathrm{H}$ NMR spectra of the bitumen (a), $\operatorname{tar}(\mathbf{b})$ and the compounded bitumen (c). 


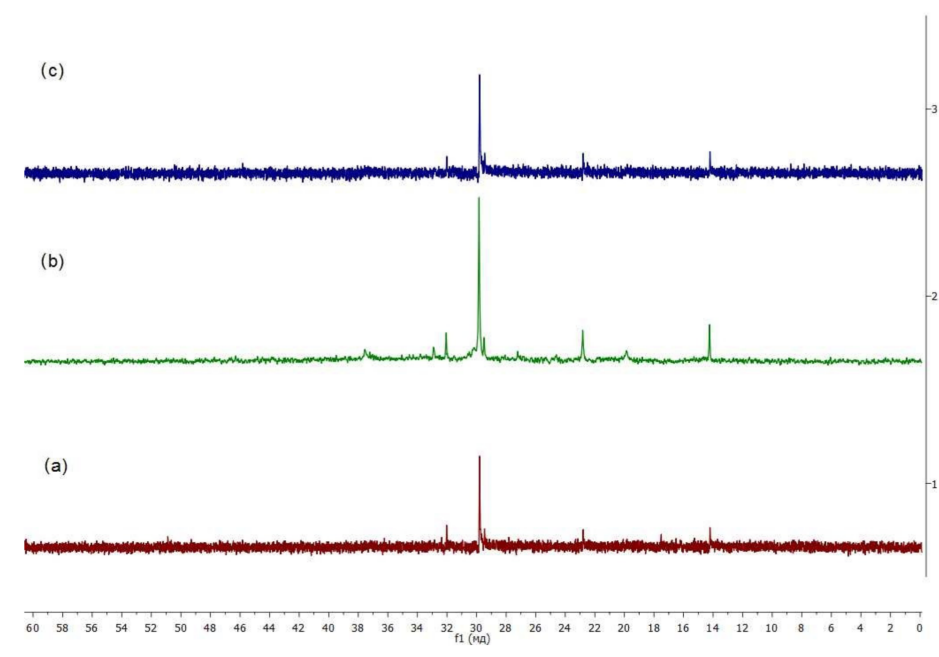

Figure 10. ${ }^{13} \mathrm{C}$ NMR spectra of the bitumen (a), $\operatorname{tar}(\mathbf{b})$ and the compounded bitumen (c).

The contents of the nuclei ${ }^{1} \mathrm{H}$ and ${ }^{13} \mathrm{C}$ in the functional groups available in the tar, the virgin bitumen and the compounded one are shown in Tables 8 and 9. The obtained results show that despite the obvious change for the group chemical composition of the bitumen by means of compounding, the distributions of hydrogen atoms in aromatic and aliphatic fragments of molecules (in functional groups) of hydrocarbons in the virgin bitumen and the compounded one remain the same: in aromatic fragments- $5.7 \%$; in aliphatic fragments-94.3\%. The highest contents $(60 \%)$ are hydrogen atoms in methylene $\left(\mathrm{CH}_{2}\right)$ and methine $(\mathrm{CH})$ groups of saturated compounds; in methyl $\left(\mathrm{CH}_{3}\right)$, methylene and methine groups in $\beta$; and further positions to an aromatic ring. A quarter of the hydrogen atoms $(25 \%)$ are in methyl groups in saturated compounds and $\gamma$ and further positions to an aromatic ring. Only $9 \%$ of the hydrogen atoms are connected directly (at $\alpha$ positions) to aromatic and carbonyl carbons, which areheteroatoms.

Table 8. Functional groups ( $\%$ under quantity of ${ }^{1} \mathrm{H}$ ).

\begin{tabular}{cccc}
\hline Type of Atoms & Bitumen & Tar & Compounded Bitumen \\
\hline $\mathrm{H}_{\alpha}$ & 9.0 & 9.8 & 9.2 \\
$\mathrm{H}_{\beta}$ & 60.0 & 59.9 & 60.1 \\
$\mathrm{H}_{\gamma}$ & 25.3 & 24.3 & 25.0 \\
$\mathrm{H}_{\mathrm{a} \ell}$ & 94.3 & 94.0 & 94.3 \\
$\mathrm{H}_{\mathrm{ar}}$ & 5.7 & 6.0 & 5.7 \\
\hline
\end{tabular}

Table 9. Functional groups (\% under quantity of ${ }^{13} \mathrm{C}$ ).

\begin{tabular}{cccc}
\hline Type of Atoms & Bitumen & Tar & Compounded Bitumen \\
\hline $\mathrm{C}_{\mathrm{pm}}$ & 10.5 & 8.3 & 9.2 \\
$\mathrm{C}_{\mathrm{pa}}$ & 17.1 & 15.1 & 8.7 \\
$\mathrm{C}_{\mathrm{a} \ell}$ & 72.4 & 76.6 & 82.1 \\
\hline
\end{tabular}

It should be also noted that the distribution of hydrogen in the above tar fragments is practically the same as in the virgin bitumen and the compounded one.

In both the virgin bitumen, tar and the compounded bitumen, no olefin group hydrogen atoms have been found. Similar results for a road bitumen and an industrial one have been obtained in the works [32,39].

A marked change in bitumen compounding occurs in the distribution of carbon atoms in specific functional groups. Thus, the total content of carbon atoms in methyl groups $\left(C_{\mathrm{pm}}+\mathrm{C}_{\mathrm{pa}}\right)$ significantly decreased (35.1\%). Meanwhile, carbon atoms in methyl groups 
bound to secondary and tertiary carbon atoms (or aromatic ring), compared to their content in the virgin bitumen, decreased by $12.4 \%$ and $49.1 \%$, respectively.

The quaternary carbon atoms $\left(\mathrm{C}_{\mathrm{a} \ell}\right)$, on the contrary, significantly increased (by $\left.13.4 \%\right)$.

Borisova T.I. and Mikhailov G.P. [40,41], by dielectric measurements, found that methyl groups connected directly to the main chain of polymers limit considerably the mobility of macromolecules. The activation energy increase by $10-30 \%$ at replacement of one of hydrogen atoms with a methyl group in ethane molecule is mentioned in Reference [42]. The above phenomena of restriction for the mobility of macromolecules in polymers and the activation energy increase in ethane molecule are explained by so-called steric obstacles created by methyl groups [42-44].

It has been also found that the reduction in methyl groups increases the mobility of the polymer chains. Thus, copolymerization of methyl methacrylate with styrene, which reduces the number of methyl groups, causes the decrease in the relaxation time, i.e., it increases the mobility of polymer units [40]. Similar results have been obtained by replacing a methyl group in polymers at the $\alpha$-position with a hydrogen atom [45]. The study for polymers of variable composition has also shown that replacement of methacrylate with acrylate (i.e., replacement of methyl group connected with $\alpha$-carbon with hydrogen atom) is followed by the disappearance of mechanical losses [43].

Aliphatic chains comprising tertiary and quaternary carbon atoms are known to be branched [46,47]. In the branched aliphatic chains, the content of simple (single) $\mathrm{C}-\mathrm{C}$ bonds of carbon atoms increased. These bonds allow free rotation of carbon atoms by $360^{\circ}$.

Thus, the significant decrease in methyl groups (35.1\%) and the considerable increase in quaternary aliphatic carbon atoms $(13.4 \%)$ providegreater mobility to the molecules and macromolecules of the compounded bitumen, which have been explained by the considerable increase in its low temperature stability.

\section{Conclusions}

The results of investigations performed in the paper have shown practical possibility for obtaining bitumen of less viscous consistency $\left(\mathrm{P}_{25}=1700.1 \mathrm{~mm}\right)$ by compounding bitumen with penetration grade 100-130 $\left(\mathrm{P}_{25}=1160.1 \mathrm{~mm}\right)$ with tar (conditional viscosity at the temperature of $80{ }^{\circ} \mathrm{C} v_{c}=82 \mathrm{~s}$ ) in the amount of $20 \%$ by weight. Meanwhile, the following is the case:

1. The effect of compounding is greater with the decrease in temperature. The tar content equal to $20 \%$ by weight is considered as an optimal one when compounding the road bitumen with penetration grade $100-130$.

2. At all the tested temperatures $\left(-24{ }^{\circ} \mathrm{C},-30{ }^{\circ} \mathrm{C}\right.$ and $\left.-36{ }^{\circ} \mathrm{C}\right)$, the stiffness of the compounded bitumen is significantly (from $18 \%$ to $34 \%$ ) lower than that of the virgin bitumen, i.e., the compounded bitumen has the increased low temperature stability.

3. The optimal compounding ( $20 \%$ of the tar by weight) increased bitumen penetration by 54 decimillimeters, which changed its original grade 100-130 to 130-200; softening point and viscosity have decreased by $5{ }^{\circ} \mathrm{C}$ and $65 \%$, respectively; Fraas point remained practically unchanged; and ductilityincreased by $10.4 \%$.

4. It has been found by adsorption chromatography that the optimal compounding significantly changes the group chemical composition of bitumen: asphaltenes and resins decreased by $23 \%$ and $8.8 \%$, respectively, and oils increased by $11.1 \%$.

5. Reduction in compounded bitumen of solid (asphaltenes) and high-viscosity (resins) components, increase in low-viscosity components (oils), as well as the decrease in the content of methyl groups in them (35.1\%), and the increase in the content of quaternary aliphatic carbon atoms $(13.4 \%)$ increase the mobility of molecules and supramolecular structures, which increases the low-temperature stability of the compounded bitumen.

6. To increase high temperature resistance of the obtained compounded bitumen, it is recommended to modify it with a polymer. 
Author Contributions: Conceptualization, B.T.; experiment, B.T., T.S., Y.A. and S.B.; writingoriginal draft preparation, B.T., T.S., C.O.R. and Y.A. All authors have read and agreed to the published version of the manuscript.

Funding: This research was funded by the Committee of Science of the Ministry of Education and Science of the Republic of Kazakhstan, grant No. IRN AP 08857446.

Institutional Review Board Statement: Not applicable.

Informed Consent Statement: Not applicable.

Data Availability Statement: The study did not report any data.

Acknowledgments: The work was performed under grant IRN AP 08857446 from the Committee of Science of the Ministry of Education and Science of the Republic of Kazakhstan. Agreement No. 230 dated 12 November 2020.

Conflicts of Interest: The authors declare no conflict of interest.

\section{References}

1. Kutiin, Y.; Telyashev, E. Bitumens and Bitumen Materials. Standards, Quality, Technologies; Publisher GUE PCP RB: Ufa, Russia, 2018.

2. The Shell Bitumen Handbook, 6th ed.; Thomas Telford Publishing: London, UK, 2015.

3. Papagiannakis, A.; Masad, E. Pavement Design and Materials; Willey \& Sons, Inc.: Hoboken, NJ, USA, 2008.

4. The Asphalt Handbook, MS-4, 7th ed.; Asphalt Institute: Lexington, KY, USA, 2007.

5. Radovskiy, B.; Teltayev, B. Viscoelastic Properties of Asphalts Based on Penetration and Softening Point; Springer International Publishing AG: Cham, Switzerland, 2018.

6. Teltayev, B.B.; Amirbayev, E.D.; Radovskiy, B.S. Viscoelastic characteristics of blown bitumen at low temperatures. Constr. Build. Mater. 2018, 189, 54-61. [CrossRef]

7. Teltayev, B.B.; Radovskiy, B.S. Predicting thermal cracking of asphalt pavements from bitumen and mix properties. RMPD 2018, 19, 1832-1847. [CrossRef]

8. Honarmand, M.; Tanzadeh, J.; Beiranvand, M. Bitumen and its modifier for use in pavement engineering. In Sustainable Construction and Building Materials; IntechOpen: London, UK, 2019; pp. 249-270.

9. Bala, N.; Kamaruddin, I.; Napiah, M. The influence of polymer on rheological and thermo oxidative aging properties of modified bitumen binders. J. Tekn. 2017, 79, 69-73. [CrossRef]

10. Abdullin, A.I.; Emelyanycheva, E.A. A study of properties of road petroleum bitumen modified with polymer additives. J. Chem. Techn. Metal. 2018, 53, 422-429.

11. Akkouri, N.; Baba, K.; Simou, S.; Elfarissi, L.; Nounah, A. Recycled thermoplastics modified bitumen improved with thermoplastic elastomer. In Proceedings of the Seventh International Congress "Water, Waste and Environment" (EDE7-2019), online, 20-22 November 2019; Volume 150, p. 02015.

12. Dekhli, S.; Mokhtar, K.A.; Hammoum, F.; Bachir, D.S. Rheological behaviour of ethylene-vinyl-acetate (EVA) modified road bitumen. J. Appl. Sci. 2015, 15, 445-455. [CrossRef]

13. Salas, M.A.; Perez-Acebo, H.; Calderon, V.; Gonzalo-Orden, H. Bitumen modified with recycled polyurethane foam for employment in hot mix asphalt. Ing. Investig. 2018, 38, 60-66. [CrossRef]

14. Porto, M.; Caputo, P.; Loise, V.; Eskandarsefat, S.; Teltayev, B.B.; Rossi, C.O. Bitumen and bitumen modification: A review on latest advances. Appl. Sci. 2019, 9, 742. [CrossRef]

15. Caputo, P.; Porto, M.; Loise, V.; Teltayev, B.B.; Rossi, C.O. Analysis of mechanical performance of bitumen modified with waste plastic and rubber (SBR) additives by rheology and PGSE NMR experiments. Eur. Chemico-Tech. J. 2019, 21, 235-239. [CrossRef]

16. Speight, J.G. Chapter 12-Environmental Aspects of Asphalt Use. In Asphalt Materials Science and Technology; Speight, J.G., Ed.; Butterworth-Heinemann Elselvier Ltd.: Oxford, UK, 2016; pp. 475-511.

17. Menzie, C.A.; Potocki, B.B.; Santodonato, J. Exposure to carcinogenic PAHs in the environment. Environ. Sci. Technol. 1992, 26, 1278-1284. [CrossRef]

18. Varjani, S.J.; Joshi, R.R.; Kumar, P.S.; Srivastava, V.K.; Kumar, V.; Banerjee, C.C.; Kumar, R.P. Polycyclic aromatic hydrocarbons from petroleum oil industry activities: Effect on human health and their biodegradation. In Waste Bioremediation; Varjani, S.J., Gnansounou, E., Gurunathan, B., Pant, D., Zakaria, A.Z., Eds.; Springer Nature: Singapore, 2018; pp. $185-199$.

19. Patent for Invention. Method of Production of Compounded Bitumen. No. RU 2302447 C, 10 July 2007.

20. Patent for Invention. Method for Bitumen Production. No. RU 2405807 C, 10 December 2010.

21. Patent for Invention. Method of Producing Asphaltite-Containing Road Bitumen. No. RU 2552469 C, 10 June 2015.

22. Imanbayev, Y.; Akkenzheyeva, A.; Bussurmanova, A.; Serikbayeva, A.; Boranbayeva, A. Preparation of polymer bitumen binder in the presence of a stabilizer. Processes 2021, 9, 182. [CrossRef]

23. Bitumens and Bituminous Binders. Oil Road Viscous Bitumens. Technical Specifications; ST RK 1373; JSC "KazdorNII": Astana, Kazakhstan, 2013. 
24. Teltayev, B.B.; Rossi, C.O.; Izmailova, G.G.; Amirbayev, Y.D.; Elshibayev, A.O. Evaluating the effect of asphalt binder modification on the low-temperature cracking resistance of hot mix asphalt. CSCM 2019, 11, 1-13. [CrossRef]

25. Tar. Technical Specifications; ST RK 3337; JSC “KazdorNII": Astana, Kazakhstan, 2018.

26. Standard Specification for Performance Graded Asphalt Binder; AASHTO M 320; AASHTO: Washington, DC, USA, 2017.

27. Standard Specification for Performance Graded Asphalt Binder; ASTM D 6373; ASTM International: West Conshohocken, PA, USA, 2016.

28. Performance Graded Asphalt Binder Specification and Testing, 3rd ed.; Superpave Series No. 1 (SP-1); Asphalt Institute Inc.: Lexington, KY, USA, 2003; pp. 1-59.

29. Standard Test Method for Effect of Heat and Air on Moving Film of Asphalt Binder (Rolling Thin-Film Oven Test); AASHTO T 240; AASHTO: Washington, DC, USA, 2013.

30. Standard Practice for Accelerated Aging of Asphalt Binder Using Pressurized Aging Versel (PAV); ASTM D 6521; ASTM International: West Conshohocken, PA, USA, 2008.

31. Standard Test Method for Determining the Flexural Creep Stiffness of Asphalt Binder Using the Bending Beam Rheometer (BBR); ASTM D 6648; ASTM International: West Conshohocken, PA, USA, 2008.

32. Teltayev, B.B.; Seilkhanov, T.M. NMR-spectroscopy determination of fragmentary composition of bitumen and its components. Eurasian Chemico-Tech. J. 2018, 20, 153-158. [CrossRef]

33. Rakhmatullin, I.Z.; Efimov, S.V.; Margulis, B.Y.; Klochkov, V.V. Qualitative and quantitative analysis of oil samples extracted from some Bashkortostan and Tatarstan oilfields based on NMR spectroscopy data. J. Pet. Sci. Eng. 2017, 156, 12-18. [CrossRef]

34. Jameel, A.G.; Khateeb, A.; Elbaz, A.M.; Emwas, A.-H.; Zhang, W.; William, L.; Robertsa, W.L.; Sarathy, S.M. Characterization of deasphalted heavy fuel oil using APPI (+) FT-ICR massspectrometry and NMR spectroscopy. Fuel 2019, 253, 950-963. [CrossRef]

35. Yen, T.F.; Erdman, J.A.; Pollak, S.S. Investigation of the structure of petroleum asphaltenes by X-ray diffraction. Anal. Chem. 1961, 33, 1587-1594. [CrossRef]

36. Dickie, J.P.; Yen, T.F. Microstructures of the asphaltic fractions by various instrumentals methods. Anal. Chem. 1967, 39, 1847-1852. [CrossRef]

37. Mullins, O.C. The modified Yen model. Energy Fuels 2010, 24, 2179-2207. [CrossRef]

38. Mullins, O.C. The asphaltenes. Annu. Rev. Anal. Chem. 2011, 4, 339-418. [CrossRef]

39. Rossi, C.O.; Caputo, P.; De Luca, G.; Maiuolo, L.; Eskandarsefat, S.; Sangiorgi, C. 1H-NMR spectroscopy: A possible approach to advanced bitumen characterization for industrial and paving applications. Appl. Sci. 2018, 8, 1-14.

40. Borisova, T.I.; Mikhailov, G.P. Investigation of dielectric relaxation in co-polymers of methylmetacrilate with sterol. High Mol. Com. 1959, 4, 563-573.

41. Mikhailov, G.P.; Krasner, L.V. Investigation of temperature dependence of dielectric losses of polymers of homological ranges for methyl acrilate and vinyl acetate. High Mol. Com. 1962, 7, 1071-1075.

42. Bartenev, G.M.; Zelenev, Y.V. Physics and Mechanics of Polymers; Higher School: Moscow, Russia, 1983.

43. Ferry, J.D. Viscoelastic Properties of Polymers, 3rd ed.; Willey: New York, NY, USA, 1980.

44. Tager, A.A. Physico-Chemistry of Polymers; Scientific World: Moscow, Russia, 2007.

45. Mikhailov, G.P.; Borisova, T.I. Regarding some peculiarities dipole-elastic losses in polymers in relation to their construction. High Mol. Com. 1964, 10, 1778-1784.

46. Ouellette, R.J.; Rawn, J.D. Organic Chemistry: Structure, Mechanism, Synthesis, 2nd ed.; Academic Press: Cambridge, MA, USA, 2019; pp. 1-39.

47. Ouellette, R.J.; Rawn, D. Alkanes and Cycloalkanes: Structures and Reactions. In Organic Chemistry, 2nd ed.; Elsevier Inc.: Baltimore, MD, USA, 2018; pp. 87-133. 